\title{
Association of Comorbidities with Coronavirus Disease 2019: A Review
}

\author{
Abhilasha ${ }^{1}$ Prasenjit Mitra ${ }^{1}$ Smriti Suri ${ }^{1}$ Taru Goyal ${ }^{1}$ Radhieka Misra ${ }^{2} \quad$ Kuldeep Singh ${ }^{2}$ \\ M.K. Garg ${ }^{3}$ Sanjeev Misra ${ }^{4}$ Praveen Sharma ${ }^{1}$
}

1Department of Biochemistry, All India Institute of Medical Sciences, Jodhpur, Rajasthan, India

${ }^{2}$ Graduate Medical Scholar, Era's Lucknow Medical College, and Hospital, Lucknow, India

${ }^{3}$ Department of Medicine, All India Institute of Medical Sciences, Jodhpur, India

${ }^{4}$ Department of Pediatrics, All India Institute of Medical Sciences, Jodhpur, Rajasthan, India

${ }^{5}$ Department of Surgical Oncology, All India Institute of Medical

Sciences, Jodhpur, Rajasthan, India
Address for correspondence Praveen Sharma, PhD, FACBI, FAMS, FAACC, Department of Biochemistry, All India Institute of Medical Sciences, Jodhpur 342005, Rajasthan, India (e-mail: praveensharma55@gmail.com).

Ann Natl Acad Med Sci (India):2020;2:102-111

\begin{abstract}
The novel Coronavirus disease 2019 (COVID-19) pandemic started with few cases of pneumonia of unknown origin in Wuhan, China. It has now become one of the significant public health emergencies of all time. Within 5 months of its existence, it has led to a significant impact on national and international policies. Apart from being a medical emergency, it is also affecting the global economy, and without proper measures, it may have severely impact the socioeconomic statuses of individuals. It has profoundly challenged the healthcare infrastructure, particularly in low- and middle-income nations. Every nation is trying to safeguard its population and the health workers as adequately as possible. While we still wait for the development of an absolute cure in the form of a vaccine, preventive measures have taken the lead in reducing the disease

Keywords

- COVID-19

- ACE2

- aging

- diabetes

- hypovitaminosis spread and breaking the chain of transmission. The knowledge gained from the clinical characteristics of patients has suggested markers or comorbid conditions that may aid in the risk assessment. This narrative review aims to provide an update on SARS-CoV-2, the causative virus of COVID-19, its pathogenesis, the clinical and laboratory features, and its association with several comorbid conditions that may influence the prognosis of this disease.
\end{abstract}

\section{Introduction}

Coronavirus disease 2019 (COVID-19) was declared as a global health crisis by the World Health Organization (WHO) on January 30, 2020. COVID-19 is not just a health crisis, as it has stressed each country of the world by creating a social, economic, and political crisis, which might leave deep scars for decades. The first case was from the city of Wuhan, China, in December 2019, with a provisional diagnosis of pneumonia of unknown origin. Gradually, more cases with similar clinical features were reported. The connection of these patients to a seafood and wild animal wholesale market in Wuhan city hinted at a new zoonosis or SARS outbreak. Further investigations were carried out for identifying this new disease. On January 7, 2020, the causative virus was isolated from a patient and its genome was sequenced. The virus, a novel member of the coronavirus family, was later named as severe acute respiratory syndrome coronavirus 2 (SARS$\mathrm{CoV}-2$ ) by the International Virus Classification Commission, and the disease was termed COVID-19 by WHO on February 11, 2020.1-4 Before COVID-19, the other Coronavirusmediated outbreaks included severe acute respiratory syndrome (SARS-CoV) and middle east respiratory syndrome (MERS-CoV). The disease had a significant spread in various 
countries of the world due to the superspreading nature of the infection, with the WHO declaring it as a global pandemic on March 11, 2020. As of May 17, 2020, the world's disease burden has reached 47,37,926 with 18,23,320 recovery and 313,636 casualties, and USA, Russia, and Spain being the most affected countries. In India, the total number of cases to date is 91,314 with 2897 deaths. ${ }^{5}$

Since the last 5 months, numerous studies are being conducted all over the world to gather information on the clinical profile and laboratory features of the patients suffering from COVID-19. The major reports, as of now, have been based on the Chinese population. COVID-19 is a highly contagious disease, mainly targeting the respiratory system. The major cause of death is due to acute respiratory distress syndrome (ARDS), with multiorgan failure in some cases. A major factor in determining the prognosis of COVID-19 is the presence of comorbidities such as age, metabolic diseases, cardiovascular diseases (CVDs), etc. ${ }^{6}$ The aim of this review was to present a comprehensive account of the virus, its pathogenesis, and the clinical and diagnostic features of the disease, besides highlighting the various comorbidities that may affect the disease progression and prognosis.

\section{Pathogenesis of COVID-19}

COVID-19 is a SARS-CoV-2 virus outbreak. As of now, its pathogenesis is not understood entirely. The data on cellular responses of this virus is undefined, but eventual pathogenesis is based on past SARS-CoV studies. The clinical course could be formulated by focusing on certain areas of the respiratory tract which are involved. ${ }^{6}$ The pathogenesis includes genome structure, transmission mode, SARS-CoV-2 infection, and replication and pathogenesis of the Coronavirus.

\section{Genome Structure}

SARS-CoV-2 is an enveloped, pleomorphic, and spherical $\beta$-Coronavirus, of size ranging from 150 to $160 \mathrm{~nm}$, with single-stranded RNA and nonsegmented nucleoprotein, capsid, matrix, and S-protein. The nucleocapsid, membrane glycoprotein, and spike glycoprotein are essential viral proteins. The extra glycoprotein coding for acetyl esterase and hemagglutination (HE) is different in other Coronaviruses. ${ }^{6,7}$ The genome of SARS CoV-2 is more like SARS-CoV than that of MERS CoV. The COVID-19 amino acid sequence is different from other Coronaviruses in the regions of the polyprotein, surface glycoprotein, and S-protein. There are two subunits of S-protein: S1 and S2; S1 being directly linked to the host receptor and S2 helping in infusion across the host membrane, both simultaneously aiding virus entry into the host cell. Studies revealed that angiotensin-converting enzyme 2 (ACE2) function as a receptor for SARS CoV-2, as it was for SARS CoV ${ }^{8,9}$

\section{Mode of Transmission}

Bats are evidently the natural reservoir for a wide variety of CoVs such as SARS-CoV and MERS-CoV. So, the SARS-CoV-2 genome was tested for BAT CoV RaTG13 and it showed 96.2\% identity, indicating that bats and SARS-CoV-2 may have the same ancestor. ${ }^{10}$ The three primary modes of transmission are droplets, contact, and aerosol transmission. ${ }^{11}$ Additionally, ocular transmission, feco-oral transmission, and vertical transmission are also reported..$^{12}$ The transmission of SARSCoV-2 mainly occurs between family members, including relatives and individuals who have closely interacted with incubation carriers..

\section{Replication and Pathogenesis of SARS-CoV-2}

SARS-CoV-2 uses the same ACE2 receptor for the cellular entry as SARS-CoV. ACE2 receptors are present in the lower respiratory tract. The S-glycoprotein virion on the Coronavirus surface is bound to ACE2 receptors on cell surfaces. ${ }^{13}$ The binding affinity of S- glycoprotein and ACE2 receptor is 10 to 20 times that of SARS-CoV. The two subunits of S glycoprotein are S1 and S2. The virus-host spectrum and cellular tropism through the receptor binding domain (RBD) are established by S1, while S2 supports he virus-cell membrane to fuse through two tandem domains: heptad repeats 1 (HR1) and heptad repeats 2 (HR2). Coronavirus genomic RNA of around 30000 nucleotides encode structural proteins and nonstructural virus proteins that are important for the synthesis of viral RNA (known as replicase-transcriptase proteins). The replicase-transcriptase proteins are determined by open reading frame 1a (ORF1a) and ORF1b, which are initially synthesized as two large polyproteins, pp1a and pp1ab. The polyproteins then split into 16 proteins during or after synthesis via virus-coded proteinases, with papain-like (PLpro) and chymotrypsin-like folds. ORF1a codes for NSP1 to NSP11 and ORF1b codes for NSP12 to NSP16. In conjunction with other viral proteins, and possibly even cellular proteins, replicase-transcriptase proteins assemble into membrane-bound replication-transcription complexes (RTCs). These complexes assemble as double-membrane vesicles in the perinuclear region. Eventually, virion-containing vesicles (VCVs) combine with the plasma membrane of the cell and release the virus. The virus then enters a new cell and continues its cycle. ${ }^{14-19}$ Replication of SARS-CoV-2 infection is explained in the - Fig. 1.

\section{Clinical Characteristics of COVID-19}

Statistics of the Chinese CDC show that $51.4 \%$ of the total infected patients are male and $86.6 \%$ lied in the age group of 30 to 79 years. The median age is 51 years ( 2 days to 100 years). ${ }^{20}$ The symptoms of COVID-19 are manifested after an incubation period of 5.2 days (1-14 days). The most 


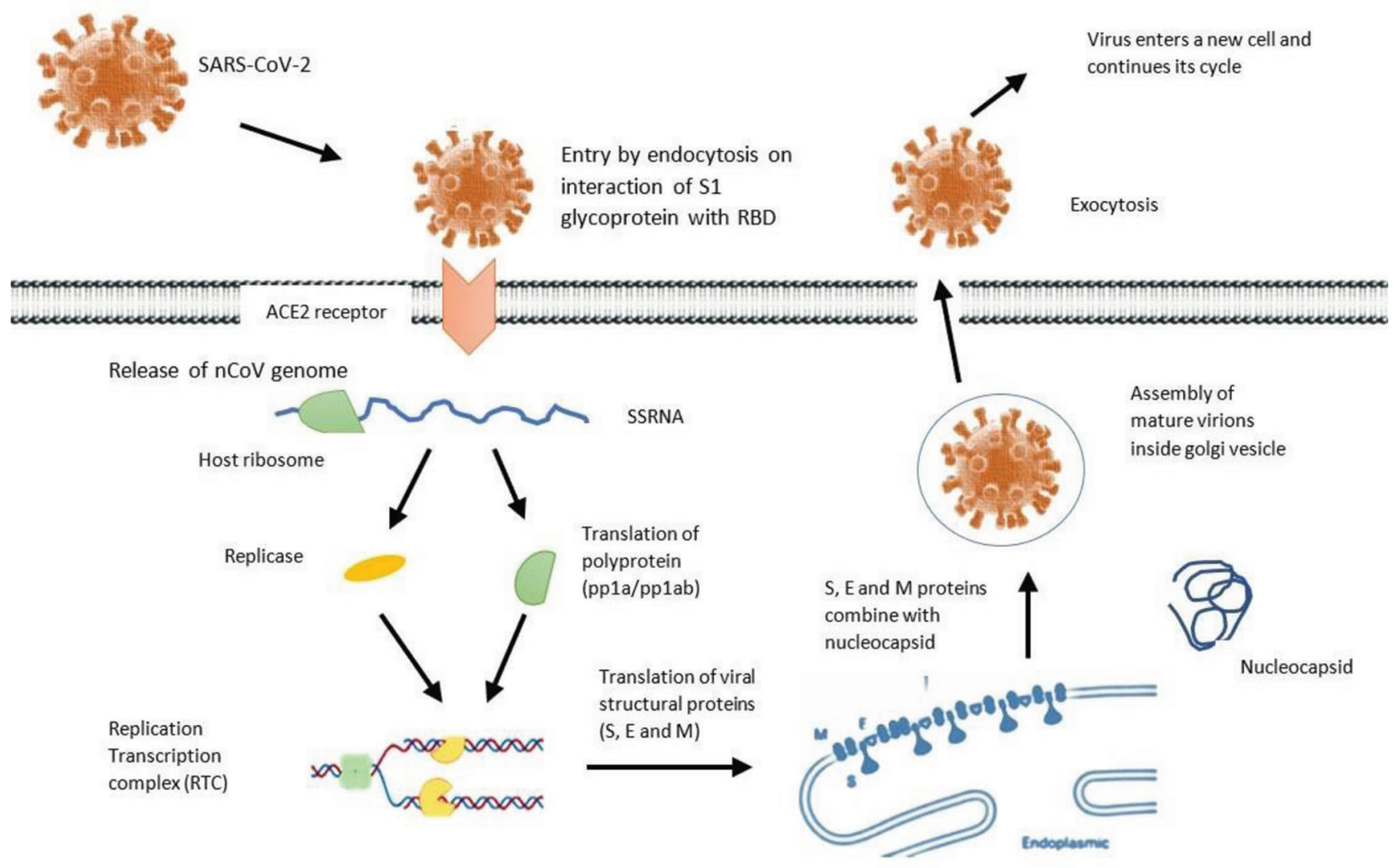

Fig. 1 Replication of SARS-CoV-2 infection.

common clinical presentation seen is fever, followed by cough, fatigue, shortness of breath, sore throat, and headache. $^{21}$ Other presentation includes sputum production, hemoptysis, diarrhea, and dyspnea. Th elderly and those patients with chronic illness rapidly develop acute ARDS, septic shock, metabolic acidosis, and even death. ${ }^{22}$

\section{Laboratory Findings and Diagnostic Modalities}

Presently, RT-PCR is the gold standard for diagnosis and regulation of SARS-CoV-2 infections..$^{23-26}$ RT-PCR is a nucleic acid amplification test (NAAT), which identifies a specific sequence of COVID-19 in the respiratory specimen. The peak viral load is seen during most of the cases during the initial onset of symptoms. This technique is expensive and time-consuming. Thus, serological testing may be considered, but it is still not approved by the Centre for Disease Control and Prevention (CDC) or any other health organization, as it detects infection in late-stage ( $>7$ days), and they may also have cross-reactivity with other coronaviruses. Additionally, SARS-CoV-2 infection is found to be associated with a dysregulation in blood investigations such as lymphocyte count, ALP, albumin, lactate dehydrogenase (LDH), C-reactive protein (CRP), and neutrophil. ${ }^{21}$ Recently, increased level of
D-dimer, CRP, prothrombin time, and procalcitonin (PCT) were considered as markers for severity of disease. ${ }^{22}$ Apart from blood and respiratory testing, radiological imaging is also considered. The early detection of subtle changes is suggested by CT. ${ }^{27}$ The standard findings from chest CT include ground glass opacities (GGOs) distributed peripherally with patchy consolidations. Increased GGO numbers, width, and density on chest $\mathrm{CT}$ is linked to the progression of the disease. A study by Quin et al stated that fluorodeoxyglucose (FDG) uptake is increased in GGOs in COVID-19 patients. ${ }^{28}$

\section{Comorbidities of COVID-19}

The clinical manifestation of the SARS CoV-2 infection has shown a wide variation in patients residing in different parts of the world. Comorbidities in addition to demographic differences and lifestyle changes are one of the most important determining factors leading to different manifestations of the disease. ${ }^{29-31}$ According to data from the early months of 2020, this catastrophe is associated with multiple severe comorbidities, with the most prevalent being old age, hypertension, diabetes mellitus (DM), coronary heart diseases, obesity, and cerebrovascular disease. These comorbidities raise the risk of hospitalization and death in COVID-19 patients dramatically. Similarly, 
the incidence of SARS and MERS was also increased in people with DM. In the USA, 34.2 million people are afflicted with DM, or 10.5 percent of the total population. ${ }^{30,32}$ of the population aged 65 years or older, $26.8 \%$ are afflicted with DM and are at greater risk of death due to COVID-19. ${ }^{30}$ Symptomatic persons with advanced age are more in need of hospitalization. This proportion ranges from 17 to 27 percent in people over 60 years. Further, in the older population, the proportion of hospitalized patients in intensive care units (ICUs) was 27 to 71 percent. However, these figures are tentative and likely to change with the prevalence of DM, hypertension, and severe obesity. ${ }^{32}$

\section{COVID-19 and Aging}

Although people over the age of 65 years constitute $17 \%$ of the total population in the USA, the CDC have estimated that they make up 31\% of COVID-19 infections, $45 \%$ of hospitalization, $53 \%$ of admissions in ICUs, and $80 \%$ of deaths caused by this infection. This means that elderly people are more likely to get infected with COVID-19 and display more severe outcomes than the general population. ${ }^{33}$ The latest proposed mechanism for SARS-CoV-2 entry in the cell is through angiotensin-converting enzyme-2 (ACE2) receptor, which is found in the lungs, heart, gastrointestinal systems, and kidneys. This particular action mechanism may suggest that older adults have a greater risk of infection. The report of the CDC says that $63.1 \%$ of adults over 60 years have hypertension, 38\% of individuals over 65 years have chronic renal disease, and $26.8 \%$ of adults over 65 years have diabetes. ${ }^{33}$ Most of the older age patients use ACE inhibitors and angiotensin-receptor blockers (ARBs), which upregulate the receptor of ACE2. It is therefore believed that the severity and probability of a severe course of infection with SARS-CoV-2 are increased for elderly people with these comorbidities, namely, diabetes, hypertension, and chronic renal disease. The common clinical presentations among 21 critically ill patients with a mean age of 70 years were dyspnea (76\%), fever (52\%), and cough (48\%). The most significant comorbidities included chronic renal disease in 48\%, CVDs in $43 \%$, chronic obstructive pulmonary disease in $33 \%$,

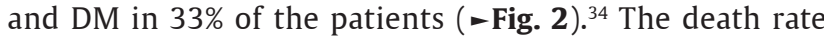
of the SARS-CoV-2 pandemic has been quite high among older adults. The total CFR (case fatality rate) of $17.3 \%$ in January decreased to $7 \%$ in February, according to the joint WHO-China fact-finding mission, but among older adults ( $>80$ years), the CFR increased to $21.9 \%{ }^{34} \mathrm{~A}$ study on 4,226 cases recorded CFR below $1 \%$ for patients under 54 years of age, but CFR of 3 to $11 \%$ for patients under 84 years of age and, finally, CFR of 10 to $27 \%$ for those over

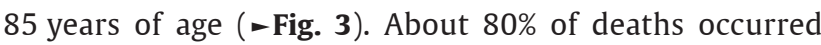
among elderly patients older than 65 years and patients with comorbidities. ${ }^{33,35}$ Increased mortality was found to be associated with diabetes among $84 \%$ of elderly patients

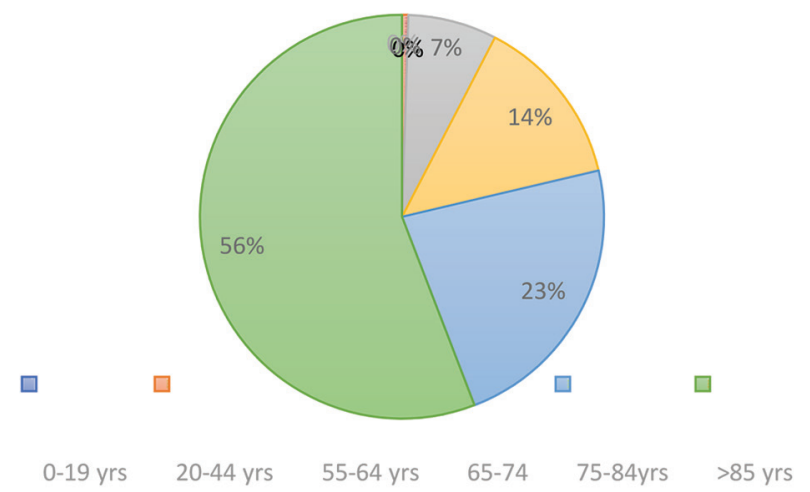

Fig. 3 Case fatality rate among SARS-CoV-2 infection by age.

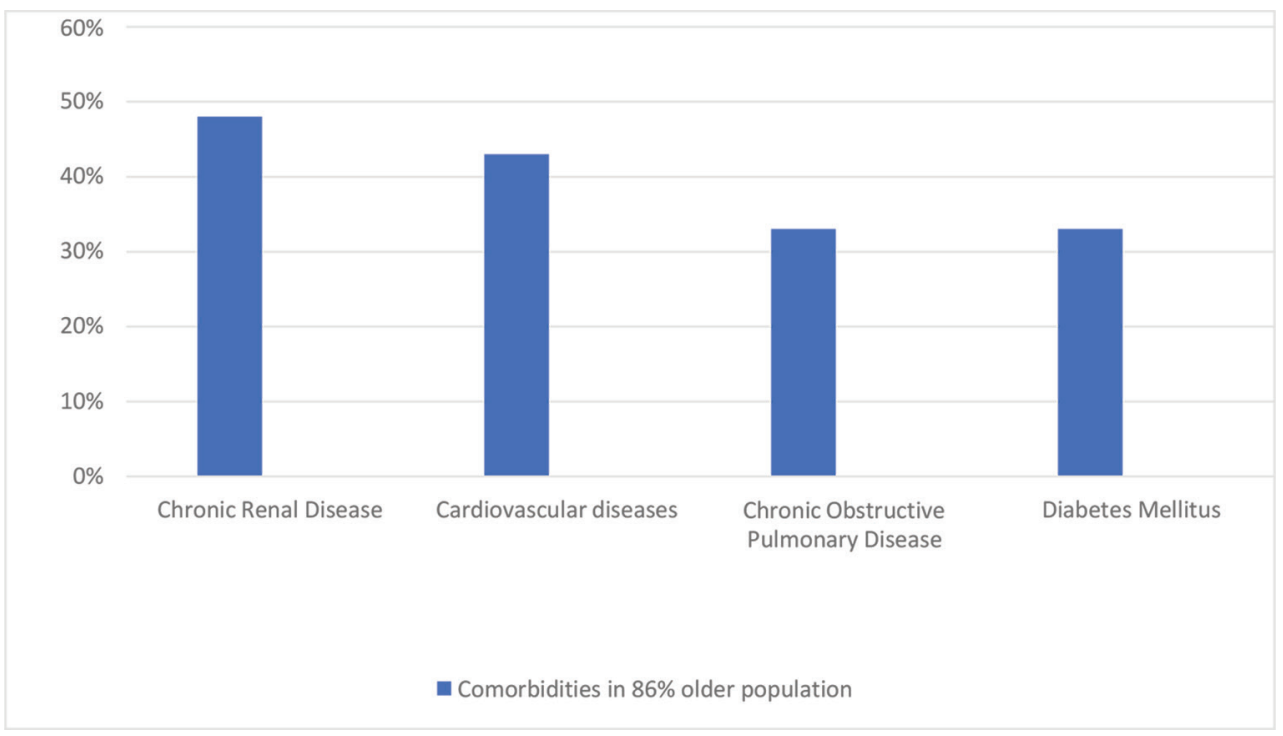

Fig. 2 Comorbidities in $86 \%$ of total older population. 
above 60 years. ${ }^{35,36}$ All these findings do suggest that old age could be a predisposing factor for developing severe SARS-CoV-2 infection.

\section{COVID-19 and Diabetes}

Almost 20 to $50 \%$ of patients afflicted with COVID-19 also suffer from DM. If COVID-19 is an acute communicable disease, DM is its chronic, noncommunicable counterpart. Both diseases can be viewed as global pandemics with different characteristics and modes of transmission, leading to their tremendous outbreaks. ${ }^{37}$ Diabetes is one of the most common and among the most dangerous metabolic diseases, marked by chronic inflammatory conditions leading to metabolic and vascular abnormalities which, in turn, affect the response toward a pathogen. Due to hyperglycemia and insulin resistance, advanced glycation end products (AGEs) are formed which, in turn, stimulate the synthesis of proinflammatory cytokines and oxidative markers, leading to tissue inflammation. ${ }^{38}$ Besides, type 2 diabetes mellitus (T2DM) is also associated with endothelial dysfunction, and enhanced platelet aggregation and activation, due to the dysregulated balance between coagulation and fibrinolysis; these abnormalities lead to hypertension and CVDs. ${ }^{39}$ Additionally, in diabetes, the immune response of the individual gets impaired to such an extent that $\mathrm{T}$ cell functions get altered, leading to changed cellular responses such as changes in neutrophil chemotaxis, phagocytosis, intracellular killing of microbes, and delayed cell-mediated immunity, eventually leading to high amounts of inflammatory cytokine secretion, which is also known as "cytokine storm." These cytokines and chemokines such as interleukin-6 (IL-6), tumor necrosis factor (TNF), CXC chemokine ligand 10 (CXCL10), and CC chemokine ligand 2 (CCL2) act as some of the major drivers of SARS-CoV-2 associated hyperinflammation and, in due course, lead to multiorgan failure. ${ }^{40}$ For a long time, diabetes was considered as one of the leading causes of morbidity and mortality throughout the world. Elderly people with T2DM are often the most vulnerable group toward infections such as influenza and pneumonia. A similar exacerbation was caused by diabetes earlier during the outbreak of SARS-CoV infection in 2002 and MERS in 2012, which affected more than 800 people in Asia and 2000 in Saudi Arabia, respectively. ${ }^{41-43}$ Considering the alarming rate of COVID-19 transmission, the association between SARS-CoV-2 and diabetes appears quite strong. The mortality rate of $16 \%$ was observed in diabetic patients afflicted with COVID-19 when compared with nondiabetics. ${ }^{44}$ In the United States, among individuals of age 65 years or above, 26.8\% were afflicted with DM, which marked a highly vulnerable group with respect to the COVID-19 toll. ${ }^{30}$ In a report from Wuhan, China, among 41 COVID-19 patients, 32\% were suffering from other comorbid conditions, with $20 \%$ suffering from diabetes. Similar findings were reported from different parts of the world, highlighting the underlying role of these disorders as predisposing factors for COVID-19. Diabetes is also associated with increased susceptibility in individuals toward infectious diseases such as Staphylococcus aureus and Mycobacterium tuberculosis, probably due to dysregulated immune responses in them. ${ }^{45-47}$

It is observed that among the diabetic patients, 29.2\% had to increase their insulin dosage, while 37.5 switched to insulin therapy from oral medicine after admission, stressing upon the deteriorating glycemic status after contracting COVID-19. ${ }^{43}$ The major link bridging the two abnormalities is the receptor protein. ACE2 on the cell surface of the liver, endocrine pancreas, kidney, brain, and heart acts as a receptor for the entry of SARS CoV-2. ACE2 regulates the synthesis and secretion of insulin hormone. ${ }^{48}$ Once the virus infects the human body, it tries to get entry into the target cell through receptor-ligand complex formation. As soon as it identifies its complementary receptors ACE2, it binds to it via spike protein and gets into the cell. ${ }^{49}$ The virus targets the endocrine pathway, thus modulating its crucial roles such as regulation of blood pressure, metabolism, and inflammation because of infection. ${ }^{49}$ ACE is an important enzyme of the renin-angiotensin system (RAS) which converts angiotensin I to angiotensin II. Angiotensin II acts as a powerful vasoconstrictor, leading to increased blood pressure, triggering oxidative stress, as well as causing a rise in reactive oxygen species (ROS). Insulin resistance, endothelial dysfunction, and proteinuria are also some of the outcomes of elevated levels of angiotensin II. ACE II uses angiotensin II as a substrate to form angiotensin 1-7, which acts as a potent vasodilator and lowers glucose and oxidative stress. Diabetic patients use ACEI and ARB drugs due to their renoprotective effects. Inhibition of ACE activity prevents the formation of angiotensin II from angiotensin but instead converts it to angiotensin 1-9 which, in turn, is further converted to angiotensin 1-7 by ACE2. Additionally, angiotensin II formed is prevented from binding to its receptor, which gets converted to angiotensin 1-7 as well. Thus, leading to balanced glucose levels and blood pressure. ${ }^{50}$ Hence, acute hyperglycemia causes upregulation of ACE2 which, in turn, facilitates the entry of the virus, and thus acts as a promotor of infection (-Fig. 4). ${ }^{49}$ It is analyzed that the combination of diabetes and COVID-19 has worsened the damage caused by both the diseases, but it is not clear whether pre-existing diabetes leads to worsening of COVID-19 symptoms or if it is the SARS CoV-2 effect which leads to progression to diabetes. The complication has arisen since the expression of ACE2 modulates $\beta$ cells functions and thus insulin secretion dysregulation.

Although there is no verification of the fact, it does point to a complicated relationship between the two severities. ${ }^{48,51-53}$ Thus, it may be suggested that DM may be an underlying factor for the rapid progression and worst prognosis of COVID-19.

\section{COVID-19 and Hypertension}

Hypertension is found in a great number of patients afflicted with severe COVID-19. The prevalence of hypertension reported in the study of 44,672 patients by China CDC was $12.8 \%$ in the overall patient community and in $39.7 \%$ in those who died. ${ }^{54}$ In patients with COVID-19, hypertension was 


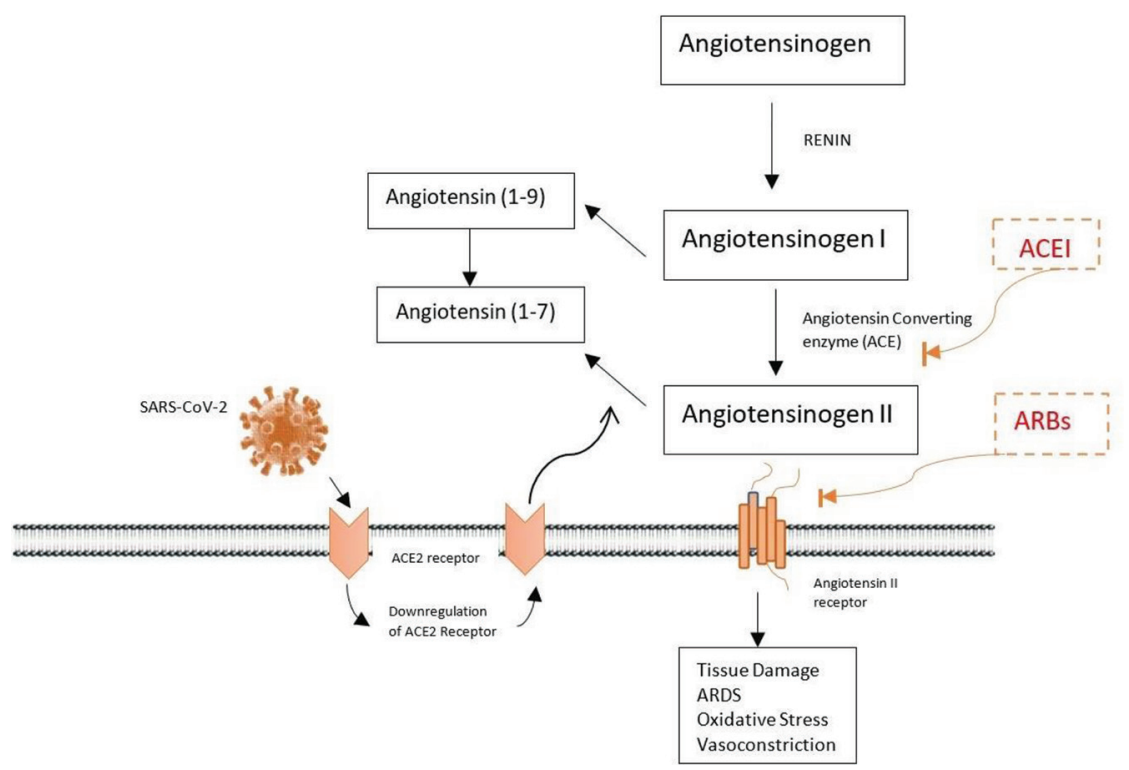

Fig. 4 Pathogenesis of SARS-CoV-2 infection and RAAS in diabetes mellitus and hypertension. RAAS, renin-angiotensin-aldosterone system.

reported to increase the death odds ratio (OR) by 3.05 (95\% CI 1.57-5.92) ${ }^{35}$ The high-prevalence of hypertension in old age may be a big concern, since aged people have poorer outcomes and a higher mortality rate compared with younger patients. According to the European Society of Hypertension, the mechanism of hypertension and severity of COVID-19 might be related to the role of the ACE2 receptor. ${ }^{55}$ ACE2 is an essential component of the renin-angiotensin-aldosterone system (RAAS), which participates in the pathogenesis of hypertension. ${ }^{56}$ ACE inhibitors and angiotensin II receptor blockers drugs inhibit RAAS which increases ACE2 levels ( - Fig. 1) ${ }^{57}$ Therefore, the institution proposes that these drugs may be harmful to SARS-CoV-2 infection..$^{58}$ The alternative mechanism connecting hypertension and COVID-19 is the immune system, and it is dysregulated in hypertension and SARS-CoV-2 infection. ${ }^{59}$ Circulating lymphocyte counts and CD8+ T cell dysfunction are observed among patients with hypertension. ${ }^{60}$ These CD8+ T cells are incapable of effectively fighting against viral infections and aid pathological cytokine overproduction, which might suggest a potential connection to COVID-19.

\section{COVID-19 and Neurological Complications}

The overall incidence of neurological complications from COVID-19 remains unclear. The neurological symptoms are mostly present in patients with severe COVID-19 compared with mild forms. ${ }^{61}$ Genome sequencing analysis revealed the presence of SARS-CoV-2 in cerebrospinal fluid (CSF) during infection, thereby suggesting neurological complications. ${ }^{62}$ There are several suggested mechanisms for the association of COVID-19 and neurological diseases. The nervous system may be involved in SARS-CoV-2 directly via hematogenous and neuronal pathways. ${ }^{63}$ The neuronal invasion of SARS-CoV-2 may be associated with the expression of the ACE2 receptor in the central nervous system (CNS). The ACE2 receptor is present in the capillary endothelial cells whereby the virus enters the endothelium and spreads to the neurons. ${ }^{64}$ Additionally, hypoxia and immune dysregulation predispose neurological involvement. SARS-CoV-2 replicates in lung alveolar cells and triggers alveolar and interstitial inflammatory exudate, leading to the formation of the membrane and subsequently, gas exchange in alveoli is severely compromised..$^{65}$ Hypoxia, in turn, causes anaerobic metabolism, interstitial edema, ischemia, and vasodilatation in CNS. Thus, syncope, an anoxic crisis, and stroke may be present. Also, SARS-CoV-2 infects macrophages, astroglia, and microglia. The disease severity and mortality are associated with cytokine storm and multiorgan failure in COVID-19 patients. An in vitro study demonstrated secretion of proinflammatory cytokines IL-6, IL-12, IL-15, and TNF- $\alpha$ from the glial cells when infected with SARS-CoV-2. ${ }^{66,67}$ The likely neurological complications include encephalitis, GuillainBarré syndrome, postencephalitic Parkinsonism, transient ischemic attack, stroke, necrotizing encephalomyelitis, and post-COVID-19 chronic fatigue syndrome. ${ }^{68}$ In a study of 214 COVID-19 patients with ARDS showed $36.4 \%$ of patients had neurological symptoms like dizziness, headache, hypogeusia, hyposmia, and change in the state of consciousness. ${ }^{68}$

\section{COVID-19 and Coagulation Abnormality}

The severe form of COVID-19 may result in sepsis-induced coagulopathy (SIC), and in uncontrolled stages, it may advance to disseminated intravascular coagulation (DIC). ${ }^{69}$ DIC is a serious complication of septicemia, cancer, pneumonia, and many other diseases. ${ }^{70}$ DIC is clinically diagnosed with a progressive decline in organ functions, which increases the development of intravascular thrombin, leading to endothelial leakage and developing secondary parenchymal bleeding. ${ }^{70}$ The immune and toxic activation of intravascular and platelet-released thrombin may contribute to the development of venous thromboembolism in COVID-19 patients. ${ }^{71}$ The diagnosis of DIC is suggested by 
the worsening of laboratory parameters. Prothrombin time (PT) and activated partial thromboplastin time (APTT) are the most common established parameters in COVID-19 patients. Thrombin-antithrombin complex, fibrin-degradation products, and D-dimers increase in the late stages of the disease, which is linked to the fatal outcome. ${ }^{72}$ Additionally, platelet counts are increased in the initial stage and decrease in the late stages of the disease. ${ }^{73}$ DIC is observed with a median time of 4 days, following the onset of interstitial pneumonia in $71 \%$ of non-survivors and $0.6 \%$ survivors. ${ }^{74}$ The D-dimer levels are three times higher in severe disease compared with mild COVID-19. The mortality rate increases three-times if the value of D-dimer is above $3 \mu \mathrm{g} / \mathrm{mL} .{ }^{75} \mathrm{CT}$ angiography revealed that COVID-19 patients with PE (pulmonary embolism) have higher levels of D-dimer than those without PE. The sensitivity and specificity of D-dimer are $100 \%$ and $67 \%$, respectively, for the PE on CT angiography. ${ }^{76}$ The current strategies of treatment for DIC and venous thromboembolism involve the use of unfractionated heparin (UFH) or low-molecular weight heparin (LMWH), which reduces the risk of mortality. ${ }^{77,78}$ Other strategies available should also be considered, such as the administration of IgG in combination with LMWH, and use of tissue plasminogen activator (tPA). ${ }^{79-81}$

\section{COVID-19 and Rheumatoid Arthritis}

The association of rheumatoid arthritis (RA) and viral respiratory infection is very complex. Few studies reported a possible role of respiratory infection in RA. ${ }^{82-}$ 84 Additionally, infections are a significant problem in patients with inflammatory arthritis, as they can lead to disease flares. ${ }^{83,84}$ RA patients are predisposed to respiratory infection compared with a healthy population. Doran et al reported that RA patients had a significantly higher risk of developing a severe form of respiratory disease compared with patients without RA. ${ }^{85}$ Another study on 2108 patients with RA also reported that RA patients had 1 - to 4-fold high risk of severe disease compared with healthy population. ${ }^{86}$ This can be linked to impairment of the immune system, as RA is an autoimmune disorder and involves the immune system. Moreover, the management of RA includes synthetic and biological disease-modifying drugs which have the potency to increase the severity of the disease, but poor control of RA has a worse effect on COVID-19. So, it is advised to continue treatment for RA. ${ }^{87}$ Recently, hydroxychloroquine was found to reduce the severity of COVID-19, which is used for the treatment of RA; also, the use of IL- 6 inhibitors like Tocilizumab was found to be beneficial in reducing the severity of COVID19 , but their use is still controversial in nature. ${ }^{88}$

\section{COVID-19 and Hypovitaminosis}

The individual's nutritional status has an impact on SARS-CoV-2 risk, the course of the treatment, and COVID-19 outcomes. Hence, macro- and micronutrient maintenance is an essential preventive measure for COVID-19. Many micronutrients are essential for improving immunity, mainly vitamin A, C, D, E, selenium, iron, and zinc. ${ }^{89}$

\section{Vitamin D}

Vitamin D plays an important role in the prevention of acute respiratory tract infections. ${ }^{90}$ Vitamin D supplementation should be started before respiratory tract infection begins. Although the underlying causes of vitamin D deficiency and the emergence of viral diseases are not clear, the possible mechanisms involve the antiviral immune stimulation, the variation of the immune defense, initiation of autophagy and apoptosis, and regulation of genetic or epigenetic mechanisms. ${ }^{91}$ Additionally, Vitamin D can lower the risk of viral infections. The associated mechanisms can be defensins and cathelicidins stimulation, which decreases the replication of the virus, increase the levels of anti-inflammatory cytokines, and decreases proinflammatory cytokines levels. ${ }^{92}$ The incidence of vitamin D deficiency is high in old age. ${ }^{93}$ The first outbreak of COVID-19 was during the winters with a high-mortality rate among the elderly, which can be linked to Vitamin D deficiency, as sunlight is the natural source of this vitamin. ${ }^{94}$ Still, for people at risk of COVID-19, vitamin D supplementation can be given in the dose of $10,000 \mathrm{IU} / \mathrm{d}$ of vitamin D3 for a couple of weeks to quickly raise the concentration of 25(OH)D, followed by $5000 \mathrm{IU} / \mathrm{d} . .^{92,95}$

\section{Vitamin C}

Several studies have reported the role of vitamin $C$ in pneumonia. However, evidence of supplementation of vitamin $C$ in the prevention and treatment of acute respiratory tract infection is unclear. Few studies have reported that the administration of vitamin $\mathrm{C}$ before and after the respiratory symptoms can be beneficial to vitamin C-deficient individuals compared with healthy individuals. ${ }^{96}$ Based on previous studies, it is revealed that the routine supplementation of vitamin $C$ can reduce the duration and severity of respiratory symptoms without any adverse effects. ${ }^{97}$ Thus, the supplementation of vitamin $C$ needs to be considered as a rational option to strengthen immunity in vitamin C-deficient individuals at risk of COVID-19.

\section{Treatment of COVID-19}

There is currently no clear and effective COVID-19 antiviral therapy. Although most COVID-19 patients have mild-to-moderate courses, up to 5 to $10 \%$ may have severe life threats, and hence there is an urgent need for specific medicines to treat the disease. The main aspect of treatment is personalized supportive care, and patients who develop ARDS require oxygen supplementation and even ventilation. Many clinical trials are under process, assuring the availability of potential vaccine and treatment for COVID-19 soon. Chloroquine, hydroxychloroquine, lopinavir/ritonavir, favipiravir, and remdesivir are the most widely used drugs worldwide. ${ }^{98,99}$ Recently, nitazoxanide and ivermectin have been documented for SARS-CoV-2 activity in vitro. Also, 
some studies have indicated the successful use of convalescent plasma therapy in severe COVID-19 patients with an increase in prognosis. ${ }^{100,101}$ All the necessary steps to monitor the emerging COVID-19 pandemic shall be enforced if the infection becomes uncontrollable. Since there is no specific treatment available to date, prevention is crucial. Isolation is recommended for suspected and confirmed cases. WHO has advised to follow social distancing, observe hand hygiene, and wear proper masks.

\section{Conclusion}

The COVID-19 pandemic, which originated from Wuhan, China, has shaken the entire globe. Although most of the patients present with mild symptoms, the spread of the infection is quite rapid. This has become a critical social health threat of this era. Since there is no treatment or vaccine available to date, the only option left is prevention. In India, a major lockdown was implemented from March 24, 2020 to contain the spread of the virus and break the chain of transmission. Despite taking all the necessary steps to contain the spread of COVID-19, the number of cases is still on the rise, majorly due to lack of awareness. The older population and individuals with chronic illness need to take extra precautions, as the mortality rate is higher among them. Although the search for a vaccine or an effective cure is still on, until then, social distancing and hand hygiene remain the best preventive measures against the fight with SARS-CoV-2.

\section{Authors' Contributions}

A. and P.M.: conceptualization; A., P.M., and S.S.: original drafting; P.M., P.S., S.M., and K.S.: proofreading, reviewing and editing; P.M., P.S., S.M.: supervision. All authors read and approved the manuscript.

\section{Conflict of Interest}

None declared.

\section{References}

1 WHO. Coronavirus (COVID-19) events as they happen. Available at: https://www.who.int/emergencies/diseases/novel-coronavirus-2019/events-as-they- happen. Accessed May 17,2020

2 Hong KH, Lee SW, Kim TS, et al. Guidelines for Laboratory Diagnosis of Coronavirus Disease 2019 (COVID-19) in Korea. Ann Lab Med 2020;40(5):351-360

3 Rothan HA, Byrareddy SN. The epidemiology and pathogenesis of coronavirus disease (COVID-19) outbreak. J Autoimmun 2020;109:102433

4 Chan JF-W, Kok K-H, Zhu Z, et al. Genomic characterization of the 2019 novel human-pathogenic coronavirus isolated from a patient with atypical pneumonia after visiting Wuhan. Emerg Microbes Infect 2020;9(1):221-236

5 Coronavirus Update (Live). 4,750,411 Cases and 313,805 Deaths from COVID-19 Virus Pandemic - Worldometer. Available at: https://www.worldometers.info/coronavirus/. Accessed May 17, 2020

6 Mitra P, Misra S, Sharma P. COVID-19 pandemic in India: what lies ahead. Indian J Clin Biochem 2020;:1-3

7 Perlman S. Another decade, another Coronavirus. N Engl J Med 2020;382(8):760-762
8 Letko $M$, Munster V. Functional assessment of cell entry and receptor usage for lineage B $\beta$-coronaviruses, including 2019-nCoV. Published online January 2020. Doi:10.1101/2020.01.22.915660

9 Dong N, Yang X, Ye L, et al. Genomic and protein structure modelling analysis depicts the origin and infectivity of 2019-NCoV, a new coronavirus which caused a pneumonia outbreak in Wuhan, China. Microbiology 2020. Doi: $10.1101 / 2020.01 .20 .913368$

10 Zhou P, Yang X-L, Wang X-G, et al. A pneumonia outbreak associated with a new coronavirus of probable bat origin. Nature 2020;579(7798):270-273

11 Yadav T, Saxena SK, Transmission cycle of SARS-CoV and SARSCoV-2. In: Medical Virology: From Pathogenesis to Disease Control Singapore: Springer; 2020:33-42

12 Alzamora MC, Paredes T, Caceres D, Webb CM, Valdez LM, La Rosa M. Severe COVID-19 during Pregnancy and Possible Vertical Transmission. Am J Perinatol 2020. Doi: 10.1055/s-0040-1710050

13 Jia HP, Look DC, Shi L, et al. ACE2 receptor expression and severe acute respiratory syndrome coronavirus infection depend on differentiation of human airway epithelia. J Virol 2005;79(23):14614-14621

14 Zhang B, Zhou X, Qiu Y, et al. Clinical characteristics of 82 death cases with COVID-19. Infectious Diseases (Except HIV AIDS (Auckl) 2020. Doi: 10.1101/2020.02.26.20028191

15 Xia S, Zhu Y, Liu M, et al. Fusion mechanism of 2019-nCoV and fusion inhibitors targeting HR1 domain in spike protein. Cell Mol Immunol 2020. Doi: 10.1038/s41423-020-0374-2

16 Yu F, Du L, Ojcius DM, Pan C, Jiang S. Measures for diagnosing and treating infections by a novel coronavirus responsible for a pneumonia outbreak originating in Wuhan, China. Microbes Infect 2020;22(2):74-79

17 de Wilde AH, Snijder EJ, Kikkert M, van Hemert MJ. Host factors in Coronavirus replication. Curr Top Microbiol Immunol 2018;419:1-42

18 Sawicki SG, Sawicki DL, Coronavirus transcription: a perspective. In: Current Topics in Microbiology and Immunology Berlin Heidelberg: Springer; 2005:31-55

19 Hussain S, Pan J, Chen Y, et al. Identification of novel subgenomic RNAs and noncanonical transcription initiation signals of severe acute respiratory syndrome coronavirus. J Virol 2005;79(9):5288-5295

20 Report of the WHO-China Joint Mission on Coronavirus Disease 2019 (COVID-19). Available at: https://www.who.int/ docs/default-source/coronaviruse/who-china-joint-missionon-covid-19-final-report.pd. Accessed May 17, 2020

21 Guan W-J, Ni Z-Y, Hu Y, et al; China Medical Treatment Expert Group for Covid-19. Clinical Characteristics of Coronavirus Disease 2019 in China. N Engl J Med 2020;382(18):1708-1720

22 Huang L, Shi Y, Gong B, et al. Blood single cell immune profiling reveals the interferon-mapk pathway mediated adaptive immune response for COVID-19. Infectious Diseases (Except HIV AIDS (Auckl) 2020. Doi: 10.1101/2020.03.15.20033472

23 Lee $\mathrm{N}$, Hui $\mathrm{D}, \mathrm{Wu} \mathrm{A}$, et al. A major outbreak of severe acute respiratory syndrome in Hong Kong. N Engl J Med 2003;348(20):1986-1994

24 Jiang G, Ren X, Liu Y, et al. Application and optimization of RT-PCR in diagnosis of SARS-CoV-2 infection. medRxiv 2020. Doi: $10.1101 / 2020.02 .25 .20027755$

25 Ai T, Yang Z, Hou H, et al. Correlation of chest CT and RT-PCR testing in Coronavirus disease 2019 (COVID-19) in China: a report of 1014 cases. Radiology 2020. Doi: https://doi. org/10.1148/radiol.2020200642

26 ThermoFisher Scientific. Random Primers \& Oligo(dT)s - IN. Available at: https://www.thermofisher.com/in/en/home/life-science/oligonucleotides-primers- probes-genes/other-dna-primers-oligos.html. Accessed May 17, 2020 
27 Yang Q, Liu Q, Xu H, Lu H, Liu S, Li H. Imaging of coronavirus disease 2019: A Chinese expert consensus statement. Eur J Radiol 2020;127:109008

28 Qin C, Zhou L, Hu Z, et al. Dysregulation of immune response in patients with Coronavirus 2019 (COVID-19) in Wuhan, China. Clin Infect Dis 2020. Doi: 10.1093/cid/ciaa248

29 Richardson S, Hirsch JS, Narasimhan M, et al; and the Northwell COVID-19 Research Consortium. Presenting characteristics, comorbidities, and outcomes among 5700 patients hospitalized with COVID-19 in the New York City Area. JAMA 2020. Doi: $10.1001 /$ jama.2020.6775

30 CDC. National Diabetes Statistics Report | Data \& Statistics | Diabetes | CDC. Available at: https://www.cdc.gov/diabetes/ data/statistics/statistics-report.html. Accessed May 17, 2020

31 Onder G, Rezza G, Brusaferro S. Case-fatality rate and characteristics of patients dying in relation to COVID-19 in Italy. JAMA 2020. Doi: 10.1001/jama.2020.4683

32 Ferguson N, Laydon D, Nedjati Gilani G, et al. Report 9: Impact of non-pharmaceutical interventions (NPIs) to reduce COVID19 mortality and healthcare demand. Available at: https://www.imperial.ac.uk/media/imperial-college/medicine/sph/ide/gida-fellowships/Imperial-College-COVID19NPI-modelling-16-03-2020.pdf. Accessed June 22, 2020

33 CDC COVID-19 Response Team. Severe outcomes among patients with Coronavirus Disease 2019 (COVID-19) - United States, February 12-March 16, 2020. Morb Mortal Wkly Rep 2020;69(12):343-346

34 Arentz M, Yim E, Klaff L, et al. Characteristics and outcomes of 21 critically ill patients with COVID-19 in Washington State. JAMA 2020;323(16):1612

35 INTENSIVE. Report of the WHO-China Joint Mission on Coronavirus Disease 2019 (COVID-19) | INTENSIVE Review. INTENSIVE. Available at: https://intensiveblog.com/reportof-the-who-china-joint-mission-onease-2019-covid-19/. Accessed May 11, 2020

36 Zhou F, Yu T, Du R, et al. Clinical course and risk factors for mortality of adult inpatients with COVID-19 in Wuhan, China: a retrospective cohort study. Lancet 2020;395(10229):1054-1062

37 Maddaloni E, Buzzetti R. Covid-19 and diabetes mellitus: unveiling the interaction of two pandemics. Diabetes Metab Res Rev 2020. Doi: 10.1002/dmrr.3321

38 Knapp S. Diabetes and infection: is there a link?-A mini-review. Gerontology 2013;59(2):99-104

39 Petrie JR, Guzik TJ, Touyz RM. Diabetes, hypertension, and cardiovascular disease: clinical insights and vascular mechanisms. Can J Cardiol 2018;34(5):575-584

40 Lingeswaran M, Goyal T, Ghosh R, et al. Inflammation, immunity and immunogenetics in COVID-19: A Narrative Review. Ind J Clin Biochem 2020. Doi: 10.1007/s12291-020-00897-3

41 Huang Y-T, Lee Y-C, Hsiao C-J. Hospitalization for ambulatory-care-sensitive conditions in Taiwan following the SARS outbreak: a population-based interrupted time series study. J Formos Med Assoc 2009;108(5):386-394

42 Chan-Yeung M, Xu RH. SARS: epidemiology. Respirology 2003;8(Suppl):S9-S14

43 Morra ME, Van Thanh L, Kamel MG, et al. Clinical outcomes of current medical approaches for Middle East respiratory syndrome: A systematic review and meta-analysis. Rev Med Virol 2018;28(3):e1977

44 Guo W, Li M, Dong Y, et al. Diabetes is a risk factor for the progression and prognosis of COVID-19. Diabetes Metab Res Rev 2020. Doi:

45 Shah BR, Hux JE. Quantifying the risk of infectious diseases for people with diabetes. Diabetes Care 2003;26(2):510-513

46 Muller LMAJ, Gorter KJ, Hak E, et al. Increased risk of common infections in patients with type 1 and type 2 diabetes mellitus. Clin Infect Dis 2005;41(3):281-288

47 Joshi N, Caputo GM, Weitekamp MR, Karchmer AW. Infections in patients with diabetes mellitus. N Engl J Med 1999;341(25):1906-1912
48 Bindom SM, Lazartigues E. The sweeter side of ACE2: physiological evidence for a role in diabetes. Mol Cell Endocrinol 2009;302(2):193-202

49 Bornstein SR, Rubino F, Khunti K, et al. Practical recommendations for the management of diabetes in patients with COVID19. Lancet Diabetes Endocrinol 2020;8(6):546-550

50 Cure E, Cumhur Cure M. Angiotensin-converting enzyme inhibitors and angiotensin receptor blockers may be harmful in patients with diabetes during COVID-19 pandemic. Diabetes Metab Syndr 2020;14(4):349-350

51 Roca-Ho H, Riera M, Palau V, Pascual J, Soler MJ.Characterization of ACE and ACE2 expression within different organs of the NOD mouse. Int J Mol Sci 2017;18(3):563

52 Yang J-K, Lin S-S, Ji X-J, Guo L-M. Binding of SARS coronavirus to its receptor damages islets and causes acute diabetes. Acta Diabetol 2010;47(3):193-199

53 Wang D, Hu B, Hu C, et al. Clinical characteristics of 138 hospitalized patients with 2019 novel Coronavirus-infected pneumonia in Wuhan, China. JAMA 2020;323(11):1061

54 Epidemiology Working Group for NCIP Epidemic Response, Chinese Center for Disease Control and Prevention. [The epidemiological characteristics of an outbreak of 2019 novel coronavirus diseases (COVID-19) in China]. Zhonghua Liu Xing Bing Xue Za Zhi 2020;41(2):145-151

55 Kreutz R, Algharably EA, Azizi M, et al. Hypertension, the renin-angiotensin system, and the risk of lower respiratory tract infections and lung injury: implications for COVID-19. Cardiovasc Res 2020. Doi:10.1093/cvr/cvaa097

56 Vaduganathan M, Vardeny O, Michel T, McMurray JJ, Pfeffer MA, Solomon SD. Renin-angiotensin-aldosterone system inhibitors in patients with Covid-19. N Engl J Med 2020;382(17):1653-1659

57 Ferrario CM, Jessup J, Chappell MC, et al. Effect of angiotensin-converting enzyme inhibition and angiotensin II receptor blockers on cardiac angiotensin-converting enzyme 2 . Circulation 2005;111(20):2605-2610

58 Danser AHJ, Epstein M, Batlle D. Renin-angiotensin system blockers and the COVID-19 pandemic: at present there is no evidence to abandon renin-angiotensin system blockers. Hypertension 2020;75(6):1382-1385

59 Drummond GR, Vinh A, Guzik TJ, Sobey CG. Immune mechanisms of hypertension. Nat Rev Immunol 2019;19(8):517-532

60 Siedlinski M, Jozefczuk E, Xu X, et al. White blood cells and blood pressure: a Mendelian randomization study. Circulation 2020;141(16):1307-1317

61 Xu Z, Shi L, Wang Y, et al. Pathological findings of COVID-19 associated with acute respiratory distress syndrome. Lancet Respir Med 2020;8(4):420-422

62 Wu Y, Xu X, Yang L, Liu C, Yang C. Nervous system damage after COVID-19 infection: Presence or absence? Brain Behav Immun 2020. Doi: $10.1016 /$ j.bbi.2020.04.043

63 Desforges M, Le Coupanec A, Dubeau P, et al. Human coronaviruses and other respiratory viruses: underestimated opportunistic pathogens of the central nervous system? Viruses 2019;12(1):E14

64 Baig AM, Khaleeq A, Ali U, Syeda $H$. Evidence of the COVID-19 virus targeting the cns: tissue distribution, host-virus interaction, and proposed neurotropic mechanisms. ACS Chem Neurosci 2020;11(7):995-998

65 Wu Y, Xu X, Chen Z, et al. Nervous system involvement after infection with COVID-19 and other coronaviruses. Brain Behav Immun 2020. Doi: 10.1016/j.bbi.2020.03.031

66 Bohmwald K, Gálvez NMS, Ríos M, Kalergis AM. Neurologic alterations due to respiratory virus infections. Front Cell Neurosci 2018;12:386

67 Mehta P, McAuley DF, Brown M, Sanchez E, Tattersall RS, Manson JJ; HLH Across Speciality Collaboration, UK. COVID-19: consider cytokine storm syndromes and immunosuppression. Lancet 2020;395(10229):1033-1034 
68 Mao L, Wang M, Chen S, et al. Neurological manifestations of hospitalized patients with covid-19 in wuhan, china: a retrospective case series study. Infectious Diseases (Except HIV AIDS (Auckl) 2020. Doi: 10.1101/2020.02.22.20026500

69 Klok FA, Kruip MJHA, van der Meer NJM, et al. Incidence of thrombotic complications in critically ill ICU patients with COVID-19. Thromb Res 2020. 191:145-147

70 Voves C, Wuillemin WA, Zeerleder S. International Society on Thrombosis and Haemostasis score for overt disseminated intravascular coagulation predicts organ dysfunction and fatality in sepsis patients. Blood Coagul Fibrinolysis 2006;17(6):445-451

71 Bikdeli B, Madhavan MV, Jimenez D, et al. COVID-19 and thrombotic or thromboembolic disease: implications for prevention, antithrombotic therapy, and follow-up. J Am Coll Cardiol 2020. Doi: 10.1016/j.jacc.2020.04.031

72 Barton LM, Duval EJ, Stroberg E, Ghosh S, Mukhopadhyay S. COVID-19 autopsies, Oklahoma, USA. Am J Clin Pathol 2020;153(6):725-733

73 Han H, Yang L, Liu R, et al. Prominent changes in blood coagulation of patients with SARS-CoV-2 infection. Clin Chem Lab Med 2020. Doi: 10.1515/cclm-2020-0188

74 Lippi G, Plebani M, Henry BM. Thrombocytopenia is associated with severe coronavirus disease 2019 (COVID-19) infections: a meta-analysis. Clin Chim Acta 2020;506:145-148

75 Tang N, Bai H, Chen X, Gong J, Li D, Sun Z. Anticoagulant treatment is associated with decreased mortality in severe coronavirus disease 2019 patients with coagulopathy. J Thromb Haemost 2020;18(5):1094-1099

76 Lippi G, Favaloro EJ. D-dimer is associated with severity of coronavirus disease 2019: a pooled analysis. Thromb Haemost 2020;120(5):876-878

77 Leonard-Lorant I, Delabranche X, Severac F, et al. Acute pulmonary embolism in COVID-19 patients on CT angiography and relationship to D-dimer levels. Radiology 2020. Doi:10.1148/ radiol.2020201561

78 Wada $H$, Thachil J, Di Nisio $M$, et al; The Scientific Standardization Committee on DIC of the International Society on Thrombosis Haemostasis. Guidance for diagnosis and treatment of DIC from harmonization of the recommendations from three guidelines. J Thromb Haemost 2013. Doi: 10.1111/ jth. 12155

79 Barrett CD, Moore HB, Yaffe MB, Moore EE. ISTH interim guidance on recognition and management of coagulopathy in COVID-19: a comment. J Thromb Haemost 2020. Doi:10.1111/ jth. 14860

80 Lin L, Lu L, Cao W, Li T. Hypothesis for potential pathogenesis of SARS-CoV-2 infection-a review of immune changes in patients with viral pneumonia. Emerg Microbes Infect 2020;9(1):727-732

81 Wang J, Hajizadeh N, Moore EE, et al. Tissue plasminogen activator (tPA) treatment for COVID-19 associated acute respiratory distress syndrome (ARDS): a case series. J Thromb Haemost 2020. Doi:10.1111/jth.14828

82 Arleevskaya MI, Shafigullina AZ, Filina YV, Lemerle J, Renaudineau Y. Associations between viral infection history symptoms, granulocyte reactive oxygen species activity, and active rheumatoid arthritis disease in untreated women at onset: results from a longitudinal cohort study of Tatarstan women. Front Immunol 2017;8:1725

83 Listing J, Gerhold K, Zink A. The risk of infections associated with rheumatoid arthritis, with its comorbidity and treatment. Rheumatology (Oxford) 2013;52(1):53-61

84 Galloway JB, Hyrich KL, Mercer LK, et al; BSRBR Control Centre Consortium; British Society for Rheumatology Biologics
Register. Anti-TNF therapy is associated with an increased risk of serious infections in patients with rheumatoid arthritis especially in the first 6 months of treatment: updated results from the British Society for Rheumatology Biologics Register with special emphasis on risks in the elderly. Rheumatology (Oxford) 2011;50(1):124-131

85 Doran MF, Crowson CS, Pond GR, O'Fallon WM, Gabriel SE. Predictors of infection in rheumatoid arthritis. Arthritis Rheum 2002;46(9):2294-2300

86 Franklin J, Lunt M, Bunn D, Symmons D, Silman A. Risk and predictors of infection leading to hospitalisation in a large primary-care-derived cohort of patients with inflammatory polyarthritis. Ann Rheum Dis 2007;66(3):308-312

87 Rutherford AI, Subesinghe S, Hyrich KL, Galloway JB. Serious infection across biologic-treated patients with rheumatoid arthritis: results from the British Society for Rheumatology Biologics Register for Rheumatoid Arthritis. Ann Rheum Dis 2018;77(6):905-910

88 Devaux CA, Rolain J-M, Colson P, Raoult D. New insights on the antiviral effects of chloroquine against coronavirus: what to expect for COVID-19? Int J Antimicrob Agents 2020;55(5):105938

89 Maggini S, Pierre A, Calder PC. Immune Function and Micronutrient Requirements Change over the Life Course. Nutrients 2018;10(10):E1531

90 Bergman P, Lindh AU, Björkhem-Bergman L, Lindh JD. Vitamin $\mathrm{D}$ and respiratory tract infections: a systematic review and meta-analysis of randomized controlled trials. PLoS One 2013;8(6):e65835

91 Charan J, Goyal JP, Saxena D, Yadav P. Vitamin D for prevention of respiratory tract infections: a systematic review and meta-analysis. J Pharmacol Pharmacother 2012;3(4):300-303

92 Teymoori-Rad M, Shokri F, Salimi V, Marashi SM. The interplay between vitamin D and viral infections. Rev Med Virol 2019;29(2):e2032

93 Grant WB, Lahore H, McDonnell SL, et al. Vitamin D supplementation could prevent and treat influenza, coronavirus, and pneumonia infections. Published online March 15, 2020. Doi: 10.20944/preprints202003.0235.v1

94 Nair R, Maseeh A. Vitamin D: The "sunshine" vitamin. J Pharmacol Pharmacother 2012;3(2):118-126

95 Holick MF. Sunlight and vitamin D for bone health and prevention of autoimmune diseases, cancers, and cardiovascular disease. Am J Clin Nutr 2004;80(6(Suppl):1678S-1688S

96 van Driel ML, Beller EM, Thielemans E, et al. Oral vitamin C supplements to prevent and treat acute upper respiratory tract infections. Cochrane Acute Respiratory Infections Group, ed Cochrane Database Syst Rev Published online March 19, 2019. Doi:10.1002/14651858.CD013292

97 Maggini S, Beveridge S, Suter M. A combination of highdose vitamin $C$ plus zinc for the common cold. J Int Med Res 2012;40(1):28-42

98 Uyeki TM, Bernstein HH, Bradley JS, et al. Clinical Practice Guidelines by the Infectious Diseases Society of America: 2018 update on diagnosis, treatment, chemoprophylaxis, and institutional outbreak management of seasonal influenza. Clin Infect Dis 2019;68(6):e1-e47

99 Liu J, Cao R, Xu M, et al. Hydroxychloroquine, a less toxic derivative of chloroquine, is effective in inhibiting SARS-CoV-2 infection in vitro. Cell Discov 2020;6(1):16

100 Syal K. COVID-19: Herd immunity and convalescent plasma transfer therapy. J Med Virol 2020. Doi: 10.1002/jmv.25870

101 Cheng Y, Wong R, Soo YO, et al. Use of convalescent plasma therapy in SARS patients in Hong Kong. Eur J Clin Microbiol Infect Dis 2005;24(1):44-46 